\title{
The Genetic Component in Child Mortality
}

\author{
D. F. ROBERTS, J. CHAVEZ, and S. D. M. COURT \\ From the Laboratory of Human Genetics and the Department of Child Health, \\ University of Newcastle upon Tyne
}

\begin{abstract}
Roberts, D. F., Chavez, J., and Court, S. D. M. (1969). Archives of Disease in Childhood, 45, 33. The genetic component in child mortality. Analysis of the causes of death in 1041 children in all Newcastle hospitals admitting children in the period 1960 to 1966 shows that genetically determined disease makes a major contribution, $42 \%$ in this series, to the total of mortality in childhood. The findings are very similar to a previous survey made in London.
\end{abstract}

In Britain little is known about the burden that genetically determined disease, assessed in terms of morbidity and mortality, imposes on our health resources. Many assume it to be so slight as not to be worth mentioning. For example, in a recent discussion of major influences responsible for fetal and infant deaths, McKeown (1967) distinguished four main causes of postnatal death: (a) accidents and infection, with mortality rates of $1 \cdot 2,4 \cdot 0$, and 3.7 per thousand respectively in the first 4 weeks, rest of the 1st year, and 1st to the 14th years, of life; (b) obstetric conditions, including maternal pregancy diseases (e.g. toxaemia), cord and placental conditions, and labour difficulties, with respective mortality rates of 5.4, 0 , and 0 in these three periods ; (c) malformations and immaturity $(5 \cdot 6,1 \cdot 3$, and $0 \cdot 7$ per thousand); and (d) other conditions, an anomalous collection including neoplasms, with mortality rates of $1.5,0.3$, and 2.5 per thousand, respectively. In each of these categories some of the deaths are likely to be due primarily to genetic endowment, but the question is how many?

Such evidence as there is suggests that the burden is considerable and is increasing. Carter (1956) examined the causes of death in three groups of children coming to necropsy at Great Ormond Street Hospital, one in 1914, one in 1934, and the third in 1954. In 1914 two-thirds of all deaths were from diseases which, since they are preventable by well-known public health measures, can be regarded as of environmental origin, such as pneumonia, tuberculosis, and a variety of infections, particularly intestinal; only $16 \%$ of deaths were

Received 29 May 1969. attributable to genetic, or partly genetic causes. There was a steady decrease in numbers of deaths from environmental causes and an increase in those of genetic origin, until in 1954 the proportion primarily attributable to environmental agencies had dropped to $15 \%$, over one-third were due wholly or partly to genetic causes, and almost onehalf were classified as of unknown aetiology, and these mainly included sundry congenital malformations and cancers of childhood. Stevenson (1959) in northern Ireland attempted to measure the genetic disease burden in terms of demands on personnel. He found that approximately $6 \%$ of all consultations with general practitioners and $8 \%$ of consultations with specialists were by patients with genetic disease; moreover, $26 \%$ of all institutional beds were occupied by patients with genetically determined illnesses; in addition, 1 in 500 of the population, quite apart from the immediate family of the patient, was occupied full time in caring for these patients. The morbidity and mortality burden is obviously already appreciable.

This finding is supported by the few reports from elsewhere. Miller (1964) notes that in the largest paediatric unit in British Columbia at any one time approximately $50 \%$ of the beds are occupied by children 'whose illnesses are solely or partially of genetic origin'. Among the 1300 patients in the Provincial School for the Retarded, more than $20 \%$ of the cases can be attributed to 'genetic or partially genetic causation', comprising by far the largest group of those with a known aetiology. The British Columbia Registry for handicapped children and adults, which attempts to register every child with a handicapping illness in the province, had about 20,000 cases on file at the end 
of 1962 , and of these approximately $75 \%$ could be 'attributed to genetic or partially genetic causes'. The United Nations Scientific Committee on the Effects of Atomic Radiation (1962) estimated that $6 \%$ of all newborn infants will at some time in their life have a defect or an illness which may be attributed entirely or partly to genetic factors. Further, an unknown but probably appreciable proportion of miscarriages, stillbirths, neonatal deaths, and sterility may be attributable to genetic factors. The figure of $6 \%$ does not include the large section of mentally retarded, nor the genetic components of susceptibility to specific infectious diseases.

\section{The Present Study}

The following study was therefore undertaken to obtain some estimate of the contribution of genetic disease to the total child mortality in a group of Newcastle hospitals. This it was hoped would complement these previous estimates of the genetic burden, and provide a basis for comparison with a similar analysis at a later date.

The data utilized were collected from the reports of deaths in children in the following institutions in Newcastle upon Tyne-Royal Victoria Infirmary, Newcastle General Hospital, Walkergate Hospital, The Babies' Hospital, Fleming Memorial Hospital.

All ill children admitted to hospital in Newcastle would come into one or other of these institutions. The first three cater for the whole age range of the population, and of these only the records of the Children's departments were considered. Monthly reports, which include deaths during the month, are furnished to the University Department of Child Health, and these provided a useful and accessible index. For the years 1960 to 1966 inclusive, the total number of deaths so recorded in these hospitals was 1067. For 26 of these, information was insufficient for any classification to be possible and these were discarded, leaving a total usable series of 1041 cases. For each of these, the causes of mortality and details of associated conditions were reviewed and classified. The genetic disease was not necessarily the immediate cause of death; for instance, in children with fibrocystic disease of the pancreas the immediate cause of death may have been pneumonia, but there is little doubt that the fibrocystic disease was the fundamental cause. The categories that were distinguished and the number of cases occurring in each are set out below.

\section{Results}

Single gene effects. Though there has been considerable modification and refinement of the classical concept of the gene, it remains very convenient for practical purposes in medical genetics to regard some diseases as due to a replaceme $\overrightarrow{\text { की }}$ t of one allele by another at a particular point on a chromosome, and showing the classical patterfs of dominant or recessive or co-dominant inhe tance. Some 600 conditions are well establish as being due to such single 'gene' substitutions, and for some 900 more the evidence is suggestive. Out of the present series of deaths, 88 cases coutd be identified as having such simple genetic diseases (Table I). Of these, 74 were recessive, 2 dominagit,

TABLE I

Simple Genetic Disease

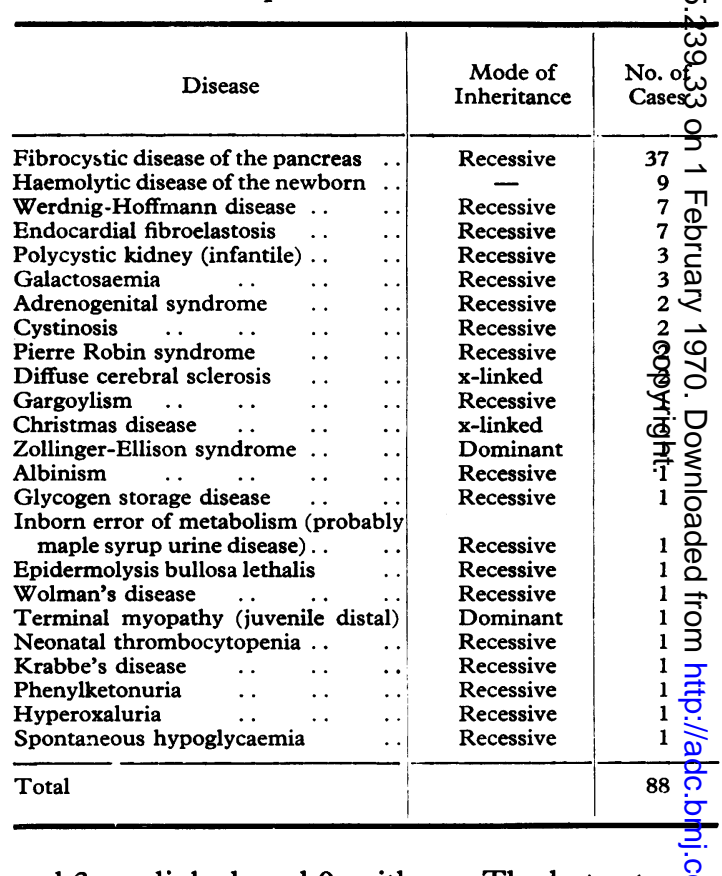

and 3 sex-linked, and 9 neither. The last category refers to haemolytic disease of the newborn whith has been included as a simple genetic disease, but naturally cannot be assigned to either recessize or dominant category since it stems from gene incompatibility of parents rather than a genetic disorder of the child himself. For other diseases, cognizance has been taken of their heterogenefly of origin, and Table I only includes those particufar forms which are due to single gene effects. For example, though deaths in cases of cleft palate occurred in the series, they occurred in casss where cleft palate was associated with harefp or other malformations, which appear to be multi- 
factorial in origin; no deaths were recorded in those cases in which the form of cleft palate is that behaving as a simple dominant trait, so there is no entry of cleft palate in Table I. Table I shows that $8.5 \%$ of deaths in the series were associated with single gene defects, and that most $(84 \%)$ of these were recessive in character.

Chromosomal disorders. A second category of genetic disorder can be easily distinguished, the conditions primarily due to numerical chromosomal aberration. Disorders in which chromosomal irregularities appear as secondary phenomena, e.g. chronic myeloid leukaemia, or are of doubtful relevance to the main disorder, were not included in this category. Table II shows that 25 of the

TABLE II

Chromosomal Disorders

\begin{tabular}{|c|c|}
\hline Disease & No. of Cases \\
\hline 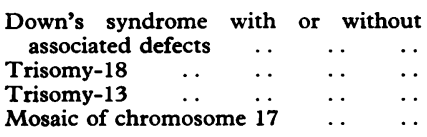 & $\begin{array}{r}22 \\
1 \\
1 \\
1\end{array}$ \\
\hline Total & 25 \\
\hline
\end{tabular}

deaths in the series occurred where there was an associated chromosomal aberration. The most frequent was Down's syndrome, with or without associated defects, which accounted for the majority $(88 \%)$ of cases. The most frequent associated defects were congenital heart conditions (in 14 cases, and in 2 of these, Hirschsprung's disease also occurred); duodenal atresia (in 3 cases, of which one also had a heart defect); in only one was leukaemia associated. Trisomy of the $\mathrm{D}$ group and trisomy of the E group both accounted for one case each, and one death occurred in a child who was a mosaic of chromosome 17. This total of 25 is a clear underestimate since chromosomal examination is not as yet done routinely, even on that part of necropsy material where there are multiple congenital anomalies. Indeed in most of the period covered by this survey no facilities at all existed for chromosomal examination.

Disorders of probable but complex genetic aetiology. In the third category were included (a) those diseases in which a genetic component is detectable by reason of their tendency to familial occurrence, but in which the pattern of hereditary transmission is not that observed in the case of single gene effects; (b) those in which a strong but complex genetic component seems likely, because of the specificity of the disorder of normal development in the absence of common extrinsic factors, and those due to persistence of some earlier embryonic stage of development again unassociated with any detectable maternal pregnancy disorder; both the latter may be interpreted as deriving from disorders of the genetic mechanisms controlling development. Diseases in this category can be regarded as due to a number of genes interacting with each other and with other factors of the milieu of development; hence the name 'multifactorial' is applied to this type of inheritance. It is in this field that much advance in understanding is currently being made. It is true that many of the disorders included in this category in the present analysis are not yet well established as multifactorial, but all such appear to be strong candidates for this type of inheritance. Though there are cases in the literature where some of these diseases, for example, spina bifida, pyloric stenosis, some forms of congenital heart disease, and forms of hydrocephalus, have been reported as behaving in particular families as though they were controlled by a single gene, such cases represent a minority, and there is insufficient proof to accept their general assignment to simple gene disorders; hence these were included in this third category and not among the manifestations considered as simple genetic disease. In a few at least of the cases in this category some chromosomal disorder is likely to have been found had it been sought.

Altogether these cases numbered 326. This category of genetic disease was thus responsible for, or at least associated with, the majority of deaths in the series. The most frequent were disorders of the central nervous system, closely followed by various congenital heart conditions (Table III).

Diseases of doubtful genetic or unknown aetiology. These conditions were the most difficult to classify. In some a slight degree of genetic influence has been postulated, yet the evidence is not sufficiently consistent to accept; in others, the effects of environment seem predominant though the specific factor is not identifiable. Others are clearly heterogeneous; for example in those low birthweight babies whose deaths are attributed to 'prematurity' there may be some aberration of the gross environmental factor, the maternal reproductive mechanism, 
TABLE III

Disorders of Complex Aetiology

\begin{tabular}{|c|c|}
\hline Disorder & $\begin{array}{c}\text { No. of } \\
\text { Cases }\end{array}$ \\
\hline 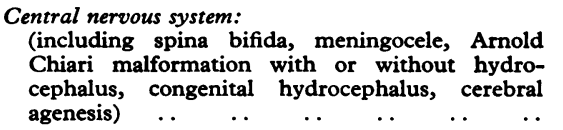 & 105 \\
\hline $\begin{array}{l}\text { Congenital heart disease: } \\
\text { (including transposition of great vessels, coarcta- } \\
\text { tion of aorta, tricuspid atresia, truncus cardiac, } \\
\text { situs inversus, cor triloculare biatriatum) }\end{array}$ & 93 \\
\hline $\begin{array}{l}\text { Alimentary tract: } \\
\text { (including atresia of intestine, imperforate anus, } \\
\text { Hirschsprung's disease, idiopathic megacolon, } \\
\text { duplication of caecum, duplication of ileum and } \\
\text { volvulus, pyloric stenosis, tracheo-oesophageal } \\
\text { fistula, malrotation of gut, oesophageal atresia, } \\
\text { annular pancreas, and duodenal atresia).. }\end{array}$ & 44 \\
\hline $\begin{array}{l}\text { Body structure: } \\
\text { (including exomphalos, cleft lip and palate, scolio- } \\
\text { sis, absent ribs, absent abdominal wall syndrome, } \\
\text { neonatal bronchiectasis, multiple congenital } \\
\text { abnormalities, dwarfism) } \\
\text {. . } \quad \text {.. }\end{array}$ & 62 \\
\hline $\begin{array}{l}\text { Hypoplasia or dysplasia of other organs: } \\
\text { (including congenital renal hypoplasia and } \\
\text { dysplasia, congenital biliary atresia, adrenal } \\
\text { hypoplasia) .. } \quad . . \\
\text {... }\end{array}$ & 14 \\
\hline 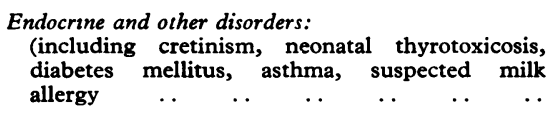 & 8 \\
\hline Total & 326 \\
\hline
\end{tabular}

but undoubtedly some cases are associated with the occurrence of some genetic abnormality in the fetus. In this group, then, the role of heredity is not known, though in some conditions it may be a possible component in the aetiology.

The group was virtually composed of two broad categories; first the various neoplasms, including leukaemia, accounting for 92 deaths (Table IV), and second low birthweight babies accounting for 51 deaths. They accounted for 143 of the 179 cases in this section of the series.

Non-genetic. Finally a series of deaths was selected in which it seemed that genetic factors were not primarily responsible (Table V). There was no doubt about causes such as road accidents, burns, etc. In this environmental group were also included deaths from specific infections, of which respiratory and gastro-intestinal predominated. Since almost every one of these deaths could have been prevented by not exposing the child to the infecting agent they are included under this heading, though it is possible that in some there is a genetic component in their susceptibility to the infecting agent. The cardiac failures in this group were independent of congenital heart diseases, and included rheumatic carditis, coronary thrombosis, and congestive heart failure from other causes. Respiratory obstructions included hyaline membrane disease, haemorrhages, and aspirations. The whole group accounted for 423 deaths.

\section{Discussion}

This series of hospital deaths should not be used to assign any quantitative value to the genetic

TABLE IV

Neoplasms

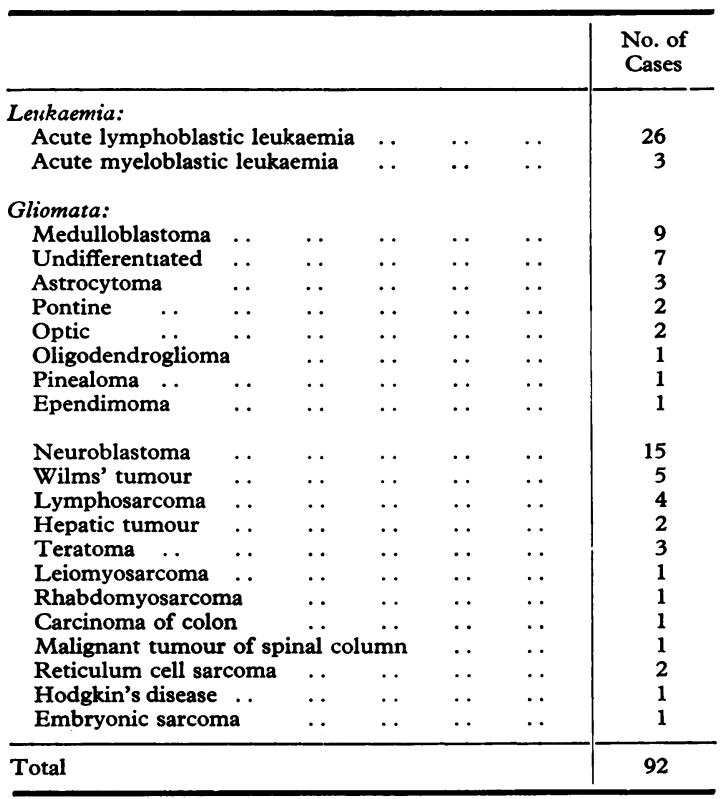

TABLE V

Environmental

\begin{tabular}{|c|c|c|c|c|c|c|}
\hline \multicolumn{6}{|c|}{ Disorder } & \multirow{2}{*}{$\begin{array}{r}\begin{array}{r}\text { No. of } \\
\text { Cases }\end{array} \\
115 \\
112 \\
63 \\
52 \\
29 \\
18 \\
11 \\
8 \\
8 \\
7\end{array}$} \\
\hline $\begin{array}{l}\text { Trauma } \\
\text { Respiratory infectio } \\
\text { Gastro-intestinal in } \\
\text { Septicaemias ... } \\
\text { Encephalitis . } \\
\text { Burns and scalds } \\
\text { Renal failure . . } \\
\text { Cardiac failure } \\
\text { Poisonings .. } \\
\text { Urinary infections }\end{array}$ & $\begin{array}{l}\text {. } \\
\text { ectic } \\
\ldots \\
\ldots \\
\ldots \\
\ldots \\
\ldots \\
\ldots\end{array}$ & $\begin{array}{l}\text {. } \\
\text { and } \\
\ldots \\
\ldots \\
\ldots \\
\ldots \\
\ldots \\
\ldots\end{array}$ & $\begin{array}{l}\text {. } \\
\text { strun } \\
\ldots \\
\ldots \\
\ldots \\
\ldots \\
\ldots \\
\ldots\end{array}$ & $\begin{array}{c}\cdots \\
\cdots \\
\text { ons } \\
\cdots \\
\cdots \\
\cdots \\
\cdots \\
\cdots \\
\cdots\end{array}$ & $\begin{array}{l}\cdots \\
\cdots \\
\cdots \\
\cdots \\
\cdots \\
\cdots \\
\cdots \\
\cdots\end{array}$ & \\
\hline Total & & & & & & 423 \\
\hline
\end{tabular}


component in child mortality in general. It may well be that these hospital deaths are not representative of deaths in children in the total population. It is not possible to check the numbers against the total deaths in these age-groups in Newcastle, since many of the cases came from outside the city; nor is it possible to compare them with the total deaths in other parts of the North-East region. Since the hospitals concerned are teaching hospitals, it may be argued that only the more rare and more interesting cases find their way to these hospitals, and thus the series may be biased towards the unusual. However, there is also an opposing bias. It is by no means unknown for children with chronic genetic disease, for whom there is no hope, to spend their last days at home in the surroundings of their immediate family, or in other institutions catering for their special group of disorders, e.g. there is no death from Duchenne muscular dystrophy in the series. Thus the bias towards overemphasis of genetic conditions, that the use of teaching hospital records may bring about, is to some extent countered by this opposing tendency.

There is also a high degree of subjectivity in the classifications used in this study. First, in a retrospective survey such as this we have been largely dependent upon the diagnosis of others, though these were in all cases experienced specialist colleagues. But a disease that can be regarded as a single entity for diagnosis and treatment, is not necessarily homogeneous in its aetiology, and there is an increasing number of genetic diseases which, apparently the same, are in fact heterogeneous in their inheritance. We have checked with case notes, investigations, and necropsy reports. We feel confident about the assignation of cases in Tables I and II. It may well be that some of the cases assigned to the categories in Tables III and IV should in fact have been attributed to single gene effects, and a few to chromosomal disorders, but in the absence of good family histories of sufficiently wide scope, and of appropriate technical investigations, we felt it wiser to place these as we have done. Thus the data in Tables I and II represent underestimates. On the other hand, environmental factors may have exerted a greater effect than allowed for, and some of the cases in Table III should perhaps have been assigned to category IV, though the converse may also be true. Of those in Table $\mathrm{V}$ there is little doubt, though to the extent that some of the infections that proved fatal may have included a genetic component of susceptibility, the importance of genetic factors is thereby underestimated.
As with all surveys and analyses of this kind, a major difficulty has been the interaction that occurs between the genetic constitution of an individual and the environment in which he develops. Few conditions are due solely to the effect of a 'gene', and a gene that produces a particular effect in one individual may not produce the same effect in another, and indeed may not produce any effect at all in a third with his different genetic constitution and different environment. In practice the concept of a continuous spectrum is useful, with at one end those diseases due to genes alone and occurring in individuals possessing those genes no matter in what environment they develop or what other genes they possess, and at the other those diseases due to environment alone, which occur in patients regardless of genetic constitution. The majority of disorders lie between these two extremes. The classification used in the present work does not consist therefore of independent discrete categories, but of the different zones of a continuous spectrum with the disorders of Tables I and II near one end, those of Table $V$ at the other, and those of categories III and IV between.

Making allowance for the evident limitations of this type of survey, the results are none the less striking. Deaths from simple genetic disease account for $8.5 \%$ and those from chromosomal aberrations for $2.5 \%$ so that together these two categories make up $11 \%$ of identifiable deaths in the series. This part of the spectrum is most clearly distinguishable. Then come $31 \%$ of the total, occurring in disorders thought to be genetic though multifactorial and complex in aetiology. Together these disorders attributable to genetic or partly genetic causes account for $42 \%$ of the deaths. The environmental end of the spectrum accounts for some $41 \%$ of the total, but here again there may well be some genetic component in resistance or susceptibility to infections which make up a considerable proportion of the total deaths in this large group. And finally there may be a further hidden genetic element in the remaining $17 \%$ of deaths here labelled 'doubtful or unknown'.

It is not easy to compare these results with those of the other authors referred to in the introduction, since details of the actual conditions included in the various parts of their classifications are not available. Carter (1956), however, lists the conditions occurring in his 1954 'genetic' group and gives a clear guide as to the types of condition included in his other categories. There is a good correspondence of those he regards as part genetic with those in our Table III, probable genetic but 
complex, and between his wholly genetic group and our single gene defect. Since his survey was done before modern methods of chromosomal analysis had been applied to man, he did not distinguish the chromosomal disorders as a separate entity and included most of them in his 'part genetic' categories (personal communication). The correspondence in definition is sufficiently strong, however, for the comparison of results in Table VI to be meaningful.

\section{TABLE VI}

Summary of Findings

$\left.\begin{array}{lr|ll}\hline \multicolumn{2}{c|}{\text { Carter's Results (200 deaths) }} & \multicolumn{2}{|c}{\text { Present Survey (1041 deaths) }} \\ \hline \text { Wholly genetic } & 12 \% & \begin{array}{l}\text { Single gene } \\ \text { defects } \\ \text { Chromosomal } \\ \text { disorders } \\ \text { Probable but } \\ \text { complex genetic } \\ \text { aetiology }\end{array} & 2 \cdot 5 \%\end{array}\right\} 11 \%$

The general correspondence in results is close. Carter's total of wholly and part-genetic combined is similar to the total of our first three categories, though there is a suggestion that in his series single gene defects are more numerous, and partgenetic less. At the non-genetic end of the spectrum there is greater difference, though the totals in the two series are similar. The nature of the two hospital populations, with Great Ormond Street predominantly a referral centre, together with the new knowledge of the 15 intervening years, probably account for most of the differences: But the central finding in this survey is clear. Genetically determined disease contributes vey considerably to the total burden of mortality in childhood in Newcastle. Newcastle, moreover, ds not unique in this, as the similarity to Great Ormongd Street shows. This similarity further suggesps that the trends that have occurred and are occurring elsewhere towards an increase in the genetic component of morbidity and mortality are als occurring in the North-East. The probability of an increasing burden of genetic disease raises mary problems in recognition and management whis क्ष् need to be faced.

Dr. Chavez, on leave of absence from the Prograni de Genetica y Radiobiologia of Mexico, is supported 6 a Fellowship from the Comision Nacional de Energia Nuclear, for which he makes grateful acknowledgmerft.

\section{REFERENCES}

Carter, C. O. (1956). Changing patterns in the causes of death the Hospital for Sick Children. Great Ormond Street fourne, No. 11., 65.

McKeown, T. (1967). Social and biological influences on foeed and infant deaths. In Social and Genetic Influences on Life atd Death. p. 43-56. Ed. by Lord Platt and A. S. Parkes. Oliver

and Boyd, Edinburgh.
Miller, J. R. (1964). Human genetics in public health resegres and programming. In Human Genetics in Public Fralth. p. 21. Ed. by L. E. Schacht. Minnesota Dept. of HE1t, Minneapolis.

Stevenson, A. C. (1959). The load of hereditary defects in humf populations. Radiation Research, Suppl. 1, 306.

United Nations Scientific Committee on the Effects of Atonix Radiation (1962). Report to the General Assembly, 1\% session, supplement 17 (A/3838). United Nations, New Yor.

Correspondence to Dr. D. F. Roberts, Laboratory $\overrightarrow{\overline{8}}$ Human Genetics, University of Newcastle upon Tyne, 19 Claremont Place, Newcastle upon Tyne NE2 4AA 